\title{
El viñedo y el vino de Ribadavia: consideraciones jurídicas bajome- dievales y de los primeros tiempos modernos
}

\author{
Ana María Rivera Medina \\ UNED
}

RESUMEN: La Denominación de Origen Ribeiro, con una extensión actual de tres mil hectáreas, arraiga su tradición en la Edad Media. El cultivo del viñedo, apoyado por la presencia de las órdenes religiosas, alcanza gran dimensión en las cuencas de los ríos Miño y Avia, en la actual provincia de Orense. En este enclave, la pequeña y concentrada villa gallega de Ribadavia, asentada en las proximidades de la confluencia del río Miño con el último tramo del río Avia, será conocida en la Baja Edad Media como la productora del vino de ribeiro, también denominado «ribadavia». Este caldo dinamizará la economía villazga, lo que se plasma en un conjunto de ordenamientos reales y municipales que imponen regulaciones proteccionistas al viñedo, a la elaboración del vino y a su comercio. La legislación refleja cómo con el desarrollo de los mecanismos legales la autoridad concejil organiza las prácticas del cultivo de la vid, la elaboración del vino y el comercio de éste; todo ello en defensa de los intereses locales. El análisis de estas regulaciones, ejes de este estudio, muestra un paisaje que da identidad a la villa y que, sin perder su carácter distintivo, se identifica con las características de la vitivinicultura europea.

\section{PALABRAS CLAVE: Viticultura; vino; ordenanzas; Ribadavia; Galicia; Ribeiro.}

\section{Ribadavia's Vineyards and Wine: Legal Considerations on Late Medieval and Early} Modern Times

ABSTRACT: The Ribeiro Denomination of Origin, with a current extension of three thousand hectares, has a tradition rooted in the Middle Ages. The cultivation of vines, supported by the presence of religious orders, reaches large dimensions in the basins of the rivers Miño and Avia, in the present province of Orense. In this area, the small and concentrated Galician town of Ribadavia, settled near the confluence of the Rio Minho 
and the last stretch of the river Avia, is known in the Late Middle Ages as the producer of ribeiro wine, also called «ribadavia.» This product boosts the town's economy, which is reflected in a series of royal and municipal ordinances that impose protectionist regulations to the vineyard, winemaking and its trade. The jurisprudence reflects how the town's authority, with the development of legal mechanisms, organizes the practices of grape growing, wine production and trade, all in defense of local interests. The analysis of these regulations, focus of this study, shows a landscape that gives identity to the village and that, without losing its distinctive character, is identified with the characteristics of European Viticulture.

KEY WORDS: Viticulture; Wine; Ordinances; Ribadavia; Galicia; Ribeiro.

\section{INTRODUCCIÓN}

En 1967, en su estudio sobre viñedos y vinos del Noroeste español, Huezt de Lemps concreta una primera imagen del viñedo de Ribadavia poniendo de manifiesto la importancia del vino «ribadavia» como producto objeto de comercio. La obra, que es un referente para los estudiosos de la vitivinicultura española, ofrece importantes datos sobre el paisaje de este viñedo y su despliegue comercial en el mercado internacional. Sin embargo, los historiadores han mostrado su interés por el tema cuatro décadas después de que la obra viese la luz. Algo en lo que mucho tiene que ver el auge del consumo de vino como elemento distintivo en las clases medias y altas durante las últimas décadas del siglo XX y los años que corren del siglo XXI. La necesidad de descubrir nuevos sabores, junto con el fomento de estudios sobre los paisajes culturales del vino, han dado como resultado que los investigadores ahondaran sobre los primeros pasos de las denominaciones de origen. El surgimiento de museos temáticos encuadrados en lo que se conoce como la cultura de la vid y el vino también han estimulado estas investigaciones ${ }^{1}$. El paisaje del viñedo de Ribadavia hoy esta calificado como protegido, y se incardina en el concepto de «paisaje cultural», según la consideración que otorga la UNESCO².

1 Es el caso del «Museo Etnolóxico de Ribadavia».

2 La decisión de definir y de proteger los llamados «paisajes culturales» se gesta en la reunión del Patrimonio Mundial de la UNESCO de 1972. El concepto se confirma y ratifica en reuniones posteriores a las que se acoge el gobierno español (1992-1993-2000 entre otras). Asimismo la Constitución Española se refiere a la protección de los llamados «paisajes culturales» considerados en sí mismos como elementos vinculados a políticas sectoriales como es el caso de la gestión medioambiental, la ordenación del territorio y la protección del patrimonio. RÖSSLER, 2009. 
Autores como Ferreira Priegue, López Carreira, Armas Castro, García Tato, Suárez Piñeiro, Santos, López Sabatel, Estévez Pérez, Antonio Rubio y Rivera Medina realizan estudios sobre el vino gallego en la Edad Media y en la Edad Moderna, mostrando múltiples y diferentes facetas: el viñedo, el vino, el comercio y la participación de las órdenes religiosas y de la comunidad judía, etc. No obstante, aún hoy no existe una investigación de conjunto sobre el paisaje del viñedo y del vino de Ribadavia que permita describir sus características, analizar los cauces que siguió la producción e identificar los factores que fueron determinantes en el proceso de europeización de un vino con características distintivas desde la Baja Edad Media.

Como punto de partida de este estudio, y pieza de una primera propuesta, es importante tomar como guía para el análisis de este paisaje las diversas regulaciones que desde el siglo XII dan cuenta de la existencia de un andamiaje institucional y jurídico que atiende a la actividad por múltiples causas: la protección del viñedo que tiene por finalidad el solucionar los problemas de autoabastecimiento, toda vez que el vino es parte de la dieta alimenticia; la intención de obtener excedentes con el fin de abrir nuevos mercados y encontrar nuevos nichos de demanda; y finalmente, la necesidad de conseguir rentabilidad económica para el concejo, la Iglesia y los particulares. Para el concejo porque a través de los impuestos que genera la vitivinicultura podrá llenar sus arcas; para la Iglesia porque disfrutará de importantes beneficios por renta de tierras y por la imposición decimal; y para los particulares porque obtendrán rendimiento del viñedo, del vino o de su comercio. De ahí la importancia de incorporar el ordenamiento jurídico como hilo conductor de nuestra pesquisa.

\section{UNA IMAGEN DEL RIBEIRO}

\section{Del viñedo y del vino}

Al igual que en las villas y ciudades europeas, en la difusión del viñedo de Ribadavia tuvo una importante implicación la Iglesia, y en especial las órdenes religiosas. Los monasterios gallegos se aprovechan de un nuevo concepto de propiedad y tenencia de la tierra; en pocos años los propios monjes y sus arrendadores consagran esos terrenos al cultivo de la vid y a la elaboración y comercialización del vino ${ }^{3}$. En realidad, la verdadera razón de estas grandes

3 En 2002 el Consejo Superior de Investigaciones Científicas organizó el «Primer Congreso Peninsular sobre la Cultura del Vino» cuyo objetivo fue analizar el carácter vertebrador del vino como elemento básico y universal de la sociedad gallega. Los estudios allí presentados intentan ofrecer una visión completa del fenómeno que afecta a todo el 
plantaciones de vid en el propio corazón de los monasterios se encuentra en la presión que los grandes comerciantes ejercían sobre los viticultores para que produjeran vinos aptos para la naciente burguesía que, como tal, demanda nuevos sabores y colores en busca de una identidad socio-económica.

Asimismo el viñedo gallego, como el europeo, se identifica con el minifundio, basado en predios de pequeñas dimensiones en régimen de propiedad o de arrendamiento, conocidos como «foros»; con explotaciones de carácter familiar que ocasionalmente precisan de mano de obra contratada ${ }^{4}$; con una estructura industrial en manos de un tercero, dada la fuerte inversión que suponen los torculares (de madera) y lagares (de piedra); y con un amplio sector de servicios dedicado a la conservación, el transporte, la distribución y el comercio del producto. Siendo el viñedo una actividad del sector primario, y el vino del sector secundario y terciario, el conjunto abarca un amplio espectro social que parte del propio viticultor y que algunas veces alcanza a factores $o$ intermediarios fuera del ámbito local: un círculo que comienza en la tierra y concluye en el mercado ${ }^{5}$. Un amplio mercado al que se accede por vía terrestre, utilizando la red viaria gallega hacia Santiago de Compostela y La Coruña; o marítima a través del puerto de Pontevedra que se convierte en el puerto natural de los caldos de Ribadavia. De hecho, a fines del siglo XV las autoridades pontevedresas se ven obligadas a proteger la cosecha local debido a la cuantiosa introducción de caldos procedentes de Orense, Milmanda y Ribadavia 6 .

Esta es la situación que parece presentar el viñedo de Ribadavia, sobre todo a partir del siglo XIV cuando se extiende no sólo por las zonas baldías sino también por las de labranza. El paisaje se reestructura, reemplazando las heredades «eno agro do pam» por viñedos ${ }^{7}$ adecuados a la topografía y al clima de la Galicia meridional por medio de «cortinas» — dispuestas en las laderas de los montes - y un sistema de aprovechamiento de la humedad atmosférica local basado en parrales soportados por estacas de madera conocidas como «horquetas» o «rodrigas». Ahora bien, en el sistema de conducción en alto o emparrado se diferencia el parral que se utiliza para dar sombra, a veces llamado pérgola, generalmente en el entorno de la vivienda e instalado

territorio gallego desde la dominación romana y evidencia la importancia del papel que jugaron las órdenes religiosas en los diversos aspectos de la actividad. GARCÍA TATO y SUÁREZ PIÑEIRO, 2005. La cultura del vino. Primer Congreso Peninsular.

4 Esto está demostrado en el caso del viñedo de Orense en donde para las tareas de cava y de vendimia se contrataba a «xornaleiros» siendo sus salarios muy elevados. En 1454 el concejo advertía sobre el gran gasto del viñedo: «por que los labradores, son caros». LÓPEZ CARREIRA, 1998: 170.

5 RIVERA MEDINA, 83 (Buenos Aires, 2009): 197-198; 2011: 4.

6 HUETZ DE LEMPS, 18 (Madrid, 1968): 216.

7 LÓPEZ SABATEL, 20 (Madrid, 2007): 188; 38 (Barcelona, 2008): 218. 
a una altura elevada, y la parra que no supera el metro y medio de altura y se sostiene con madera de madroño, de roble, de castaño o de pino joven ${ }^{8}$. Es más, como demuestra Huetz de Lemps, existen contratos de los siglos XII al XIV donde aparece descrito el viñedo rodeado de castaños, árboles que cumplían una doble función porque además de utilizar su madera para fabricar los tutores para las cepas, proporcionan alimento, las castañas.

Las características topográficas y climatológicas del terreno propiciaron la construcción de muros de contención para los «socaldos» o «bancales», que favorecen un mayor grado de insolación a las plantas. De esta imagen daba cuenta Alfonso X «El Sabio» que, por haber vivido de niño en Maceda, reconoce la calidad de los caldos de ribeiro. Una calidad avalada por las propias técnicas de laboreo, que han hecho emerger una cultura material donde las tareas, las medidas y los utensilios adquieren una sonoridad propia: «esterca», «enrama», «bima», «esfolla», «vimbios», «composta», «chantar» o «cepar», «ontrechantar» (mogronear), «enxertar», «cavaduras», «ferrados»9.

Aún se pueden considerar otros factores por los que el cultivo de la vid conforma un paisaje socio-económico particular. En relación a la tenencia y al trabajo del viñedo, la existencia de viñas arrendadas por cristianos y otras arrendadas por judíos dota a la villa de mayor variedad de oferta, ya que se elaboran dos tipos de caldos: cristianego y judiego ${ }^{10}$. Aunque en este punto las fuentes son escurridizas. Es evidente que, fuere cual fuere el tamaño de la comunidad hebrea, las prescripciones religiosas se cumplirán: «que el vino no sea tocado por mano de gentil». Pero además, una vez elaborado el vino, se abría por tierra o por mar un horizonte comercial en el que participan vecinos de la villa, cristianos o judíos (para estos últimos, viñas y vino se convirtieron en instrumento de crédito y pago, en mercancía del comercio asentado en la red de intercambios y relaciones con las juderías de la zona); vecinos de Pontevedra, propietarios de viñas en la villa o no; como rentistas que adelantan recursos en tiempo de vendimia y que se ocupaban del transporte marítimo desde el puerto pontevedrés hacia el mercado europeo del Báltico o del Mediterráneo ${ }^{11}$. En este sentido, es importante destacar que en la labor de intermediación los judíos o conversos juegan un papel fundamental, tanto por su potencial financiero, por sus contactos o por su capacidad de movilización de capitales, cerrando así el círculo comercial del vino de ribeiro. Los mecanis-

8 CASTRO PÉREZ, 2006, RIVERA MEDINA, 6 (San Sebastián, 2010); 2011. LÓPEZ CARREIRA, 1998: 169-170.

9 RIVERA MEDINA, 2011: 5. JURADO, 2001. LÓPEZ SABATEL, 20 (Madrid, 2007): 210.

10 ANTONIO RUBIO, 2005: 131-147; RIVERA MEDINA, 20 (Madrid, 2007): 199-233. CANTERA MONTENEGRO, 19 (Madrid, 2007): 13-48; 84 (Buenos Aires, 2010): 39-59.

11 FERREIRA PRIEGUE, 1988: 180-181. ANTONIO RUBIO, 2005: 142-143. 
mos de comercialización debieron ser ágiles considerando que la vida útil del caldo no excede el año. Al mismo tiempo el aprecio por el vino nuevo, joven, oloroso, fino y frío aumenta entre las clases dirigentes. Estos dos factores son importantes a la hora de valorar la difusión de su consumo en un amplio marco geográfico. Luego es posible suponer que además del esmero en la elaboración existiera un complejo aparato artesanal que asegurase la perdurabilidad del caldo hasta el consumidor.

\section{Del comercio del ribeiro y sus circunstancias}

Es conocido por todos que las peregrinaciones a Santiago de Compostela suponen desde el siglo XII una gran movilización. Por tierra y mar, desde diversas procedencias, llegaban personas de la más variada condición para visitar la tumba del Apóstol. El alcance de esta circunstancia ha sido estudiado como fenómeno que no se limita a un peregrinaje simbólico sino que, además, propicia el crecimiento económico de aquellas ciudades y villas ubicadas en las proximidades de las diversas rutas, favoreciendo decisivamente el auge de las actividades económicas de Santiago de Compostela. Ferreira Priegue señala que la situación fue la más propicia para que llegaran comerciantes - mitad navegantes, mitad marineros- que introdujeron en el mercado sobre todo productos suntuosos. Estas travesías ampliaron los horizontes gallegos, y ya en el siglo XII se concretó una ruta de navegación y comercio desde Londres y Flandes hasta Santiago ; un itinerario en el que Galicia cumplía un papel pasivo, es decir, limitado a la importación, toda vez que aún no existían las condiciones requeridas por un marco exportador ${ }^{12}$. El inicio del fenómeno jacobeo supone, por tanto, un acicate para el comercio de los productos gallegos, especialmente pescado y vino. Y si hablamos de vino, hablaremos del vino de Ribadavia, Ribeiro. Y si mencionamos la ciudad de Santiago, se ha de pensar en las diversas comunidades que destacan como grandes consumidores de los vino del Avia, cuestión que queda reflejada en los libros de cuentas del Hospital Real que se aprovisiona cada año de vino de Ribadavia, tal y como demuestra Gelabert ${ }^{13}$.

Pero aún hay más. Ya para los siglos XIII y XIV existe una ruta marítima consolidada para el vino de Ribeiro, amparada en la conformación de asociaciones portuarias cuyo fin principal es la protección mutua, como sucedió con la creación de la Hermandad de la Marisma (1296); ruta también escudada en la aparición de una legislación relativa al tráfico marítimo, como lo fueron los Rôles de Oléron (referencia emblemática del Derecho mercantil-Derecho co-

12 FERREIRA PRIEGUE, 1988: 190.

13 GELABERT GONZÁLEZ, 85-86-87 (Santiago, 1976): 151 y ss. 
mún de los siglos XII-XVIII de Europa) y las Leyes de Layron o Leyron $^{14}$,versión castellana de las primeras. De esta manera, las bases reguladoras del tráfico marítimo se asientan al compás del desarrollo de este derecho mercantil, creándose jurisdicciones mercantiles al margen de la jurisdicción común. Y al mismo tiempo que la tecnología se desarrolla, se institucionaliza el circuito, y se promueven las ferias y los mercados ${ }^{15}$. Todo ello regido por este reglamento, que se concibe con el fin de resolver los conflictos que plantean fundamentalmente los intercambios de vino.

Sin embargo, en el caso del vino de Ribavadia parece que existe un factor más que tiene que ver sobre todo con la contienda bélica previa a la consolidación de las monarquías más que con la propia coyuntura comercial. Galicia, y concretamente Ribadavia, padeció la incursión del Duque de Lancaster (1386), quien mediante esta ocupación intenta reclamar la Corona de Castilla apoyado por parte de la aristocracia gallega y por el gobierno portugués. Dicha incursión ha quedado recogida en la Crónica de Froissart ${ }^{16}$. Y este no es un dato menor, porque repercutirá en el comercio de los vinos de la villa. El vino ya era apreciado en el mercado inglés, pero es en este periodo cuando se ofrecen más posibilidades para su exportación. Similar situación se observa para el comercio de vinos portugueses (Lisboa, Aveiro y Porto). En 1353, 1373 y 1384 los portugueses firmaron con la Corona inglesa tres tratados vinculados directamente al comercio de vino ${ }^{17}$.

Esta relación diplomática-comercial afecta, aparentemente, al comercio del vino de Ribadavia desde varios ángulos: la ruta desde los puertos ingleses hacia Portugal recala en La Coruña y en Pontevedra; en uno de los tratados mencionados figuran como testigos representantes de la aristocracia gallega; por estas mismas fechas están documentados cargamentos de vino portugués al puerto de Pontevedra, y otros desde este puerto a la costa portuguesa y a puertos ingleses. Además, Pontevedra es el punto de encuentro de las comunicaciones por tierra entre Santiago y el sur de Portugal, y de aquéllas por mar con la carrera atlántica-mediterránea; y por último, es precisamente en este periodo cuando aparece, en palabras de Ferreira Priegue, una Galicia madura y con una fuerte estructura administrativa y económica: régimen de aduanas, industria pesquera, industria de construcción naval, infraestructuras portuarias financiadas por los concejos, grupo de mercaderes y áreas de servicios dedicadas a diversas actividades ${ }^{18}$. De lo cual se puede colegir que al ser Ponteve-

14 PORRAS ARBOLEDAS, 2005: 233. SERNA VALLEJO, 2006: 59; 2005: 112; 2004: 299.

15 LADERO QUESADA, 1994: 15.

16 ESTEVEZ PEREZ, 10 (Ourense, 2001). ANTONIO RUBIO, 2004.

17 VIÚLA DE FARIA y MIRANDA, 11 (Porto, 2010): 110-116.

18 ARMAS CASTRO, 1992: 181-185. Además, los puertos tenían puentes que dividían 
dra puerto de escala, la oportunidad para el Ribeiro estaba servida, y parece que la villa hizo buen uso de la coyuntura, ya que por estas fechas existe constancia de la presencia de comerciantes gallegos de vino de Ribadavia en dicho puerto, así como de exportaciones de este caldo a enclaves ingleses.

Dentro de este marco, el vino de Ribadavia competirá en el mercado local con los caldos procedentes de Castilla, Aragón, Lisboa, Oporto, Andalucía y Pontevedra (como el Ullao, un vino rosado de poca perdurabilidad y de una producción irregular a la baja). Pero el más demandado por la burguesía de las villas y ciudades gallegas es el vino de Ribadavia, que tiene el privilegio de entrar en Pontevedra entre septiembre y diciembre (lo que puede llegar a ocasionar una saturación de la oferta de los transportes y de los productos) donde además de ser el principal caldo consumido por los lugareños, es el más exportado. Pontevedra no es el único puerto que recibe vinos del Avia; también lo hacen Vigo, Lugo, La Coruña, Finisterre. Y llega a ser tal la importancia de este comercio que a mediados del siglo XVI el concejo de La Coruña en su empeño por evitar los fraudes delimita de manera detallada y precisa la zona vitícola: «que el vino de Ribadavia ha de ser de la villa de Ribadavia hasta el puente de San Clodio de las partes siguientes: primeramente la feligresía de San Payo... San Andrés de Camporredondo, Esposende, Pazos hermos hasta llegar a la dha Puente de San Clodio toda la orilla del río Avia y de allí revolver el río abajo Veytes, Beade, Carballeda, San Cristóbal de Rigodeygon, Ribadavia» ${ }^{19}$.

Paralelamente a la expansión del comercio del Ribeiro hacía el Atlántico sur y las Islas Británicas, desde mediados del siglo XIV se comprueba la presencia de «ribadavias» en los puertos del Cantábrico: Cuatro Villas ${ }^{20}$ (Cantabria), Asturias ${ }^{21}$, Vizcaya ${ }^{22}$ y Guipúzcoa ${ }^{23}$; durante prácticamente todo el año.

la zona de ría del área marítima. En torno a estos puertos se organizaron zonas de servicios. Este modelo es extensible a todas las villas marineras dependientes de rías en Europa.

19 AHRG, leg. 26362.

20 Sobre Cuatro Villas (Cantabria) se tiene noticia de la presencia de viñas desde 1262 en Santander. Ahora bien, la producción fue siempre insuficiente por lo cual el vino se convirtió en mercancía de importación. SOLÓRZANO TELECHEA, 1 (Santander, 2007): doc. 20, 76.

21 Un primer testimonio de 1498 sobre el comercio de vino de Ribadavia con Asturias se refiere en una causa realizada con el robo de ciertos números de botas de vino de Ribadavia que transportaban desde Galicia unos vecinos de Gijón. Información sobre el robo de vino. AGS, REG, legajo, 149803, 376. Asturias debió recurrir a las importaciones de vino dada la precariedad de sus terrenos para el cultivo de la vid. Dichas importaciones se realizan utilizando los puertos de Avilés, Gijón, Ribadesella y Llanes. Para la ciudad de Oviedo existe una ordenanza de 1515 y otra de 1518 sobre el arrendamiento de la sisa del vino con una renta anual de ocho mil maravedíes donde se manifiesta las importaciones del vino de Ribadavia, su precio y la expedición en tabernas. Además a lo largo del siglo XVI el aumento del consumo es paralelo al de su precio, lo que lleva al concejo a ordenar que se venda a un precio 
En algunos casos son los navegantes de las villas del Cantábrico quienes llegan hasta Pontevedra en busca del vino. Es más, en 1399 se promulgan en la villa de Bilbao las «Ordenanzas Municipales de Bilbao sobre producción y venta del vino» ${ }^{24}$ en las que figura un apartado que ofrece un listado de los caldos que se importan, y entre los que se citan los procedentes de La Rochela, Galicia, Castilla, Andalucía y Portugal, y en 1492 un documento, relativo a un pleito que mantienen los mareantes con las autoridades pontevedresas, menciona la venta a vizcaínos, bretones y a otros extranjeros de vino blanco de Ribadavia «e lo llevan por sobre mar» ${ }^{25}$.

Estos testimonios demuestran, al menos en el papel, la existencia de un circuito comercial entre los puertos atlánticos y los situados en el golfo de Vizcaya. Ahora bien, es evidente que a pesar de las dificultades de la navegación - desastres, piratas, corsarios, problemas jurídicos- los ingleses dominaron el comercio del vino hasta la Guerra de los Cien Años, momento en que el precio del vino de Gascuña aumenta. Ambas situaciones provocaron la desarticulación de las redes de comerciantes ingleses que operaban realizando un comercio triangular con Castilla ${ }^{26}$.

Esta coyuntura parece afianzarse con la sustitución de la oferta francesa por vino de la costa atlántica, especialmente el procedente de los puertos que siguen la línea costera desde La Coruña, el sur portugués hasta la costa andaluza, nodo fundamental para el comercio mediterráneo. Por otra parte, no podemos dejar de ver cómo a partir de la consolidación de la llamada «Marisma de Castilla» en 1404 — concordia firmada entre los puertos que hay desde Fuenterrabía hasta Tuy más los de la Gascuña inglesa ${ }^{27}$ - las redes comerciales que comprenden los marcos vasco-castellano, astur-cantábrico y galaicoportugués están articuladas y en expansión; expansión que se materializa a lo largo del siglo XV. El desarrollo de las villas marineras como San Sebastián, Bermeo, Bilbao, Castro Urdiales, Avilés, La Coruña y Pontevedra alcanza notoriedad por la existencia de una tupida red de puertos organizados, que aportan fuerza de trabajo, infraestructura portuaria y marinera, y puntos de redistribu-

previamente establecido. Lanza García, Ramón, “El viñedo en la España Cantábrica: una larga tradición ahora renovada”, pág. 7.

22 RIVERA MEDINA, 19 (Madrid, 2006): 199; 2011: 13; 6 (San Sebastián, 2010): 618-620.

${ }^{23}$ En los ordenamientos de San Sebastián de 1489 también se refieren al vino gallego. AYERBE IRÍBAR, 40 (San Sebastián, 2006): 11-91.

24 BFA/AFB, Municipal, Bilbao 0199/001/026. Privilegio que otorgó Enrique III. Puede verse la trascripción en: ENRÍQUEZ FERNÁNDEZ, 1999, doc. 47.

25 HUETZ DE LEMPS, 18 (Madrid, 1968): 214.

26 VIÚLA DE FARIA y MIRANDA, 11 (Porto, 2010): 119.

27 FERREIRA PRIEGUE, 2005: 165 y ss. Concordia firmada en 1404 entre los puertos de la Gascuña inglesa y los puertos de la «Marisma e costera de Espanna de tanto quanto se estiende e diga e tiene de la villa de FuenteRavia fasta la çiudat de Tuy». SOLÓRZANO TELECHEA, 1998. 
ción de mercaderías. Es imprescindible destacar que el influjo y el dinamismo económico de estas pequeñas, pero abundantes, villas marítimas, también se extendió por las rutas terrestres hacia todas las regiones del interior ${ }^{28}$.

$\mathrm{Y}$ es comprobable que el Ribeiro se consume en todas ellas, tal y como queda demostrado en una Real Cédula firmada por los Reyes Católicos en 1488 donde se lee: «para que los vecinos de Ribadavia e sus tierras puedan vender el vino a quien quisieren ${ }^{29}$. Este documento que puede ser entendido como un aval de libertad comercial indica que el circuito mercantil que se inicia en Ribadavia era rentable para el municipio y para la Corona; que el vino excedía con creces las expectativas de mercado y, finalmente, que la aceptación por parte de los consumidores quedaba contrastada.

\section{LA LEGISLACIÓN VILLAZGA}

\section{El Fuero de 1164}

Sabido es que, el fuero o los fueros municipales se conceden a las villas o agrupaciones humanas más desarrolladas, mejor dotadas de organización municipal, con actividades económicas consolidadas y de interés para prestar servicios a la monarquía, ya sea por estar situadas en lugares estratégicos o por cumplir una función destacada dentro del orden que se pretendía establecer desde la autoridad. Y, sin duda, responden a una mayor afirmación del poder real frente a los nobles o señores. Evidentemente la villa de Ribadavia cumple con estas características y su viñedo es objeto de atención por las instituciones y por su fuero.

El viñedo de Ribadavia es un viñedo controlado y protegido, tanto por las autoridades civiles (concejo) como por las eclesiásticas (órdenes). Y así se demuestra cuando Fernando II de León promulga en Allariz el Fuero de Ribadavia, expedido el 14 de febrero de $1164^{30}$. Este documento evidencia que para poder regular la vida urbana y poner fin a los litigios existentes la villa tiene necesidad de controlar la presión que ejercían los señores feudales. Así pues, el Fuero adopta disposiciones de carácter tributario, regula el devenir económico y social de la villa, y establece disposiciones de carácter jurídico

28 ARÍZAGA BOLUMBURU, 35 (Sevilla, 2008): 26.

29 Real Cédula de los Reyes Católicos. AGS, REGS, 12, 207. 1488. De esta real cédula existe copia dentro de un expediente firmado por el procurador general en 1574, AHRG, C355, f.111-112.

${ }^{30}$ Fuero de Ribadavia. AHN, 98.2.8/Toca, CP. 396, D.2. Trascripción y comentario en López Martínez, Amalia, Losada Meléndez, María José y Enjo Nabío, María Asunción, “O Foro de Ribadavia”, págs.10-18. 
con sus respectivas penas (sanciones pecuniarias); pero sobre todo refleja el lugar que ocupa el vino en la vida de la villa. Del documento interesa destacar la quinta disposición «Et hominis de isto burgo uendant panen suum et uinum per mensuram rectam quando uoluerint». Es decir, el interés que la villa despierta en la Corona radica fundamentalmente en el comercio del vino local.

Esta disposición no hace sino sólo confirmar que el viñedo y el vino estaban asentados con anterioridad, y que ejercían de estímulo para el desarrollo de la vida de la villa. Pero llega más allá, otorgando a sus vecinos la libertad de comerciar con el producto del viñedo, lo que igualmente significa que para ese tiempo ya existían circuitos mercantiles en torno al vino. Sin embargo, dentro de la libertad expresada, dictamina las penas a abonar en caso de transacción fraudulenta: «Factores pabun et uinum aut uenditores non pectent aliquid pro uenditione sed su mensuras fraudauerint constitutas a concilio pectent $\mathrm{V}^{\mathrm{e}}$ solidos domino d (sic) isto burgo». Pero además legitima la autoridad del concejo en relación a cuatro cuestiones en concreto: la regulación de las medidas; la percepción de las multas o penas pecuniarias; el establecimiento de regulaciones fiscales relativas al vino de «bestia gardada de pane uel de uino I denarium», impuestos que pasarían a formar parte de la caja municipal; y, finalmente, disposiciones relativas a la presencia y a la actuación de los comerciantes.

De todo ello se deduce que el Fuero se ocupa de ordenar y de regular la vida social, económica y judicial de la villa, protegiendo las actividades económicas; regulando el sistema fiscal municipal, cuestión vital toda vez que los municipios se autofinancian; controlando el deambular de los forasteros; y por último, dando un marco legal que protege a los vecinos. Pero sobre todo legisla las primeras ordenanzas sobre el comercio y los comerciantes de vino, como presagiando la amplitud del sector en los siglos posteriores. En resumen, se trata de un alegato del municipio como institución reguladora, proteccionista e intervencionista en menoscabo del poder de los señores y a favor del poder real, estrechando la relación entre la villa y la Corona. También representa una muestra de la importancia del vino como agente dinamizador de la vida urbana.

\section{Las Ordenanzas municipales}

Analizar los ordenamientos municipales supone una ardua tarea, sobre todo para los tiempos bajomedievales, donde las lagunas informativas impiden hacer una explanación cronológica completa de los mismos. Empero, es factible hacer un recorrido por las escasas fuentes y extraer un marco regulador local. Asimismo, son importantes los datos que sobre ordenamientos ofrecen do- 
cumentos posteriores, sobre todo los correspondientes a la primera mitad del siglo XVI en la medida que insertan ordenanzas precedentes. La recuperación de los ordenamientos municipales ha sido posible por la documentación que obra en el Archivo Histórico General de Galicia, la que se conserva en el Archivo Histórico Provincial de Orense y la que se encuentra en depósito en el Museo Etnolóxico de Ribadavia.

En el Archivo Histórico del Reino de Galicia ${ }^{31}$ las disposiciones están contenidas en un expediente de época posterior a la que analiza en este trabajo $(1579)^{32}$ pero que incorpora ordenanzas antiguas recopiladas en 1517, lo que permite reconstruir el universo legal de fines del siglo XV y comienzos del siglo XVI. En el Archivo Histórico Provincial de Orense, fondo Municipal de Ribadavia, en el libro correspondiente a la cuentas de los procuradores generales de la villa (1569-1574), existen informaciones desde 1532. Procedentes del Museo Etnolóxico, el «Libro de Foros Antiguos de Ribadavia», que según el inventario comprende los años de 1524 a 1541, pero que en realidad comienza hacia 1523, incluye nuevos ordenamientos. También lo hacen el «Libro de Actas del Concejo de Ribadavia» entre los años 1541 y 1559 y el «Libro de Procuradores» de 1566 y de 156733 .

Aunque las fechas exceden los límites medievales, constituyen una fuente de gran interés porque se refieren a ordenanzas antiguas, tanto en vigencia como suprimidas. Evidentemente son regulaciones sueltas, entremezcladas con documentos de otra naturaleza como foros, actas, informes y cuentas, que se citan o utilización cuando surge un problema en concreto pero que permiten vislumbrar la evolución del aparato legal del viñedo y del vino. El conjunto de fuentes, convenientemente ordenadas y cruzadas, ofrece una imagen medidamente acabada del universo vitivinícola desde los tiempos bajomedievales. Sin descartar la existencia de ordenamientos más antiguos, es posible demostrar que desde fines del siglo XV hay testimonios que ratifican la voluntad pública de regular este universo consciente de que la producción de la vid y el comercio de vino de Ribeiro vertebran el desarrollo de la villa ante la incipiente aparición del capitalismo moderno. Al mismo tiempo, para este trabajo, es relevante la legislación generada durante el siglo XV en dos ciuda-

31 Pleito Hospital de los Ángeles de Ribadavia y Amaro Fernández, su administrador con la Justicia y Regimiento de la villa y mayordomos que fueron del dicho hospital en otros años. AHRG, legajo 24330.

32 Estas ordenanzas fueron transcriptas en 1971 por Parrilla Hermida.

33 Libro de Foros Antiguos de Ribadavia (1524-1541). Arquivo Municipal de Ribadavia. MER: Depósito Rubén García Álvarez, 07. Libro de Ayuntamiento (1541-1559). Arquivo Municipal de Ribadavia. MER: Depósito Rubén García Álvarez, 54/02. Libro de Cuentas de los Procuradores Generales de la Villa de Ribadavia (1566-1567). Arquivo Municipal de Ribadavia. MER: Depósito Rubén García Álvarez, 47/02. Libro de Cuentas de los Procuradores Generales de la Villa $(1569,1573,1574)$ AHPO, Caja 325. 
des cercanas: Orense y Pontevedra.

Enjo Babío y De Antonio Rubio analizaron las ordenanzas municipales de Orense promulgadas en el siglo $\mathrm{XV}^{34}$. Entre tanto, López Carreira, al estudiar la sociedad urbana de la misma ciudad, advierte de la importancia de estos ordenamientos y se manifiesta sobre su aplicación. Armas Castro lo hace para la ciudad de Pontevedra. Es evidente el paralelismo legal de las regulaciones de estas ciudades con relación a las que se analizan en este trabajo. Si bien existió una política estratégica sobre la protección del viñedo y la producción vitícola, la tendencia se acentúa en número y en grado cuando se trata de legislar sobre la defensa del mercado local, a fin de potenciar los vinos propios, la venta intramuros y en los arrabales (mesones y tabernas), la política de precios y todo lo relacionado con el envasado, trasvase, trasiego y transporte del vino $^{35}$.

De estas disposiciones se desprende que el vino, como objeto legal, juega un papel primordial frente a otras producciones del lugar. Asimismo, se demuestra que el producto se aprecia en sumo grado porque, más tarde, regaría los mercados europeos. Son regulaciones que atienden, especialmente, a la dinámica comercial, lo que evidencia el interés municipal por vigilar, proteger y controlar los mercados, legislando precisamente para éstos. O lo que es lo mismo, el ayuntamiento «se cura en salud» regulando a la actividad comercial por ser ésta el principal instrumento de financiación urbana.

De la relectura de los documentos indicados, especialmente del emitido en el año 1579, hay que destacar que sus autores explican las razones por las que cree conveniente promulgar estas ordenanzas: «persuadido el Concejo de la cosecha del vino para la prosperidad del país». Asimismo expone cómo se procedió a su elaboración: «el señor alcalde hizo que se ayuntasen y recopilasen y coligieren todas las dichas ordenanzas antiguas y se hicieren otras mas nuevas, añadiendo, quitando, revocando o limitando aquello que parece conforme al tiempo». Es evidente que el legislador es plenamente consciente de lo que supone el vino para las rentas de la villa, y cree oportuno reafirmar esta posición con nuevas disposiciones. Acto seguido hace la indicación «como es de tiempo y costumbre inmemorial», de lo que se deduce que las nuevas regulaciones mantendrán las prescripciones de los años inmediatamente anteriores y también de las más antiguas. ¿Y cuáles son las precedentes mediatas e inmediatas?

El autor del documento revela una cuestión que es trascendental para la deriva de este trabajo: estas ordenanzas tomaron como base las regulaciones

34 ENJO BABÍO y ANTONIO RUBIO, 119 (Santiago, 2006).

35 RIVERA MEDINA, 19 (Madrid, 2006): 255-261; 14 (Zaragoza, 2008): 193-194. LÓPEZ VILLALBA, 24 (Madrid, 2011): 161. RODRIGO ESTEVAN, 1997: 575-580. 
promovidas desde la Baja Edad Media y que fueron recopiladas en $15177^{36}$. Y esto es lo que interesa al objeto de este estudio, porque dicha recopilación comprende, si no la totalidad, parte de las regulaciones anteriores al año de 1517, ratificadas posteriormente en 1579. Además, en otros tres cuerpos documentales existen ordenamientos sueltos sobre el vino que, independientes de las conocidas como ordenanzas municipales, corresponden a los años 1523-1541, 1541-1559 y 1566-1567-1569-1573-157437, y de los que también se ocupará este texto. De resultas, se desglosarán las regulaciones que abarcan desde la Baja Edad Media hasta 1579.

\section{Sobre el viñedo}

Los ordenamientos consultados no hacen referencia al viñedo como tal, es decir, no mencionan cuestiones relativas a las tareas del viñedo (cavas, podas, mugroneados-mogroneados) exceptuando a la vendimia, ni a sus trabajadores permanentes (miembros de la familia o jornaleros especializados como los podadores); tampoco lo hacen sobre las directrices relacionados con la distribución y la funcionalidad de los viñedos, porque se entiende que esto corresponde a los particulares. Sin embargo, tratan todo lo que respecta al aspecto público del viñedo; es decir, aquello que desde fuera puede incidir negativamente para su natural desarrollo. De puertas hacia adentro el viñedo depende de su dueño o arrendatario. Ahora bien, el concejo se aplica, en consecuencia, en defender los intereses de los particulares cuando desde el exterior se infringe la frontera particular y se atenta contra la producción ${ }^{38}$.

Como ya se sugirió para los estudios de Ourense y de Pontevedra, lo primero que se intenta ordenar es la regulación relativa al viñedo. Es de suma importancia que en los meses anteriores a la vendimia se alejara cualquier causante de daños porque corría peligro la cosecha venidera. Tal y como se ha comprobado para otras villas y ciudades castellanas, aragonesas y vascas, las autoridades instan a cercar los viñedos para evitar la entrada de humanos y de animales que pudieran perjudicar las vides. En algunos casos se comprueba la presencia de «veladores» o «guardaviñas» en épocas inmediatamente anteriores a la vendimia, designados por el ayuntamiento, cuya misión es cus-

36 Copia de las ordenanzas de la villa de Ribadavia, AHRG, legajo 24330, f. 96r.

$37 \mathrm{La}$ documentación correspondiente al periodo comprendido entre 1566 y 1574 se encuentra en el Libro de Cuentas de los Procuradores Generales de la Villa de Ribadavia, AHPO, Caja 325 y MER, 47/2.

38 «Que las bestias y sus cuidadores estén en los meses de junio a setiembre en el monte por el mucho daño que hacen a las viñas» Copia de las ordenanzas de la villa de Ribadavia, AHRG, legajo 24330, f. 101r. 
todiar de día y de noche los cultivos. La intromisión en viñedo ajeno es duramente castigada con penas pecuniarias elevadas para los infractores o para los propietarios de los animales (por lo general la legislación se refiere a la irrupción de ganado porcino, vacuno y ovino).

El concejo no duda en tomar precauciones cuando de la producción se trataba ${ }^{39}$. Para ello estableció que cada año los llamados «veedores del viñedo» $\mathrm{y}$ «veedores del vino» informaran sobre la madurez de la uva. Con estos datos se decide en qué momento se iniciará la vendimia. No es una cuestión menor, porque si se cosechaba con anterioridad a esta fecha el vino obtenido no sería tal, sino «agraz», es decir vino de uva verde (inmadura). Si el vino no tiene suficiente calidad, y esto dependía entre otros factores del grado de azúcar de la baya, el producto no tendría buena salida en el mercado. En otras palabras, con este capítulo el concejo se asegura que la uva tuviese el grado necesario para satisfacer el gusto de la demanda, porque es evidente que para estas fechas ya puede hablarse de una marca «vino de Ribadavia».

Ahora bien, la autoridad local tampoco pierde la oportunidad de regular el pago de los vendimiadores. Como sucede en otros sitios de Castilla, País Vasco y Aragón, las nóminas de los trabajadores contratados se suelen abonar en dinero o en especie, en este caso en vino. Asimismo se ocupa de las llamadas dietas que corresponden a la alimentación diaria de los vendimiadores compuesta por cierta cantidad de vino y de pan- a las que considerada como un complemento salarial del personal contratado. De ahí que se disponga sobre el mosto para los vendimiadores.

\section{Sobre el vino}

Los ordenamientos sobre la producción de vino abundan, particularmente regulando la protección de su calidad. Una cuestión nunca menor: el concejo debe conseguir, a través de instrumentos legales, un producto de calidad sostenida a lo largo del tiempo para mantener una demanda en alza. No es redundante decir que el ayuntamiento ejerce un control y un cuidado extremo sobre la actividad vinícola ${ }^{40}$ : regulaba las zonas desde las que no se debía

39 «Que ninguna persona pueda vendimiar sin que primero sea señalado por el regimiento; y si antes de esta algun particular tuviera necesidad de mosto para dar a los vendimiadores que lo haga con permiso de los jueces», Copia de las ordenanzas de la villa de Ribadavia, AHRG, legajo 24330, f. 103r.

40 «Que en ningún tiempo se pueda meter vino alguno en ningún tiempo del año de la otra parte del río mino, ni dende el riguero de jubín para fuera, ni dende el puente de pazos para arriba, ni dende regadas arriba, ni dende cenlle y nazara arriba, ni dende lacea de montan de mendo abaxo, ni dende la baronza arriba y desde los dichos términos a dentro se pueda meter en la villa el bino blanco y tinto. El blanco hasta el dia de San andres y el tinto hasta el 
introducir vino en la villa, defendiendo la calidad de su producción como parte de las estrategias del mercado. Así, protege a los comerciantes que se acercan a la villa pero, sobre todo, ampara al consumidor, teniendo muy en cuenta sus exigencias y la disponibilidad de caldos de calidad. Y además considera los requerimientos del mercado: el prestigio de los vinos de Ribadavia. De hecho, la pena que impone este capítulo es muy elevada: seis mil maravedíes, cada vez. El proteccionismo se comprende y justifica debido a la constatación de las grandes bolsas de fraude generadas en torno al vino, particularmente por su condición de alimento, de medicina y de mercancía del comercio. Razones que utilizan los defraudadores al ser descubiertos.

Otro capítulo particularmente importante, que también tiene que ver con el fraude y el engaño, se refiere a la mezcla de caldos de diversas procedencias ${ }^{41}$. El texto sugiere que se protege y estimula la producción local, entendiendo por tal la jurisdicción villazga, calificada de calidad superior frente a la procedente del entorno cercano. Es dable decir que en este caso en concreto el ayuntamiento hacía las veces de consejo regulador, tal y como sucede hoy con las Denominaciones de Origen. Igualmente, el texto de este capítulo redunda sobre la necesidad de preservar la calidad del vino local, y ahonda en los modos de efectuar el fraude, pues da entender que el viticultor también es proclive a mezclar caldos para obtener mayor rentabilidad de su producción, comprando vino de zonas cercanas con el que rellenar las cubas del vino de la villa.

\section{Sobre el comercio, los precios y los impuestos}

Los intercambios entre las villas y sus arrabales constituyen un verdadero problema en el Bajo Medioevo ${ }^{42}$. La relación entre ambas entidades fue presa del establecimiento de jurisdicciones difíciles de delimitar, del crecimiento de la población y del desarrollo inusitado de los suburbios como refugio de industrias y artesanías varias, y como lugar de residencia de aquellos individuos

dia de de San martino y no de alli en adelante ni de ninguna parte (...) porque de donde no se coje bueno ay gran daño e inconveniente, porque debajo de una cuba de buen vino venden los mercaderes otro que es tal y los compradores después se hallan engañados y no es vino que se pueda cargar sobremar», Copia de las ordenanzas de la villa de Ribadavia, AHRG, legajo 24330, 103v.

41 «Que ninguno mezcle el vino de su labra con el de compra si lomezclare, sea todo avido de por compra y le sea puesto precio por el juez», Copia de las ordenanzas de la villa de Ribadavia, AHRG, legajo 24330, f. 103v.

42 «Que no se vendieran ni fuera de la villa ni en sus arrabales ni vino, ni pan, ni pescado, ni aceite, ni otros mantenimientos», Copia de las ordenanzas de la villa de Ribadavia, AHRG, legajo 24330, f. 98v. 
que por diversos motivos se arriman a las villas o ciudades. Los arrabales crecían en la misma medida que las murallas constreñían la ampliación de infraestructuras urbanas. Y en este sentido el suburbio es percibido como una amenaza, y no sin razón. Entendido el arrabal como centro del fraude, las villas intentan por todos los medios frenar los trasiegos, las ventas y los negocios ilegales, sobre todo de los productos básicos para el buen desarrollo de la economía, de los vecinos y de los residente intramuros. En Ribadavia esta lucha fue continuada y denodada. La muestra más palpable es que este capítulo procura marcar los límites a los habitantes y residentes extramuros; pero el mal y los conflictos se mantuvieron en el tiempo. De tal manera que el perjuicio fue constante, tanto que los pleitos entre villa y arrabal constituyen un fenómeno de larga duración que se encuadra en el desarrollismo industrial y comercial del periodo.

El proteccionismo villazgo está también amenazado por la existencia de arrieros, quienes con el pretexto de introducir mercancías necesarias para el abastecimiento de villas y ciudades desestabilizaban el mercado local con productos que competían directamente con sus homólogos locales ${ }^{43}$. Esta cuestión particular constituye un capítulo recurrente en todo tipo de ordenamientos. La situación es incontrolable a pesar de la imposición de grandes penas, de guardas en los límites y de controles a la cargas. En Ribadavia, la permanencia y recurrencia del gremio lastra los empeños del concejo por preservar un vino de calidad. Pero además, como ya se ha indicado, a la villa llegan vinos de Castilla y de otras partes generando incertidumbre en el mercado local. Y el municipio, a golpe de ordenanza, pretende contener los excesos, no con buenos resultados a la vista de las veces que a lo largo del periodo se repite la advertencia.

Otro tema pertinaz en los ordenamientos es el que compete a los pesos y medidas ${ }^{44}$. Este es un punto de especial interés. Si bien los Reyes Católicos regularon esta cuestión, es el ayuntamiento quien debe controlar la situación. Para realizar esta tarea delega en un fiel o en un arrendador el uso y control de los llamados pesos y medidas. La función de este individuo es complicada y su figura a veces cuestionada por moverse en el filo de la legalidad. Básicamente debe constatar que los envases contienen lo declarado. Este control es complicado en tanto y en cuanto se juega con las mermas, porque a veces se compensan con vinos de otra clase o calidad; se modifica la capacidad de los envases (cubas, barriles y toneles); o se manipulan las medidas en el caso de las ventas al menudo (azumbre, etc.). Este tipo de desviaciones son muy comunes, además de sencillas, porque en la villa todos

43 «Que los arrieros no metan vino de fuera», Copia de las ordenanzas de la villa de Ribadavia, AHRG, legajo 24330, f. 103v.

44 «... todos aquellos que utilicen pesos y medidas de un tercero para pesar vino y que los pesos y medidas estén guardados en una caja, cuya llave tenga el fiel», Copia de las ordenanzas de la villa de Ribadavia, AHRG, legajo 24330, f.101v. 
tienen acceso tanto al vino propio como al ajeno. Por mucho que los pesos y medidas (vara de medir) se guarden en el ayuntamiento, los pícaros encuentran diversas maneras de desvirtuar la capacidad de un envase. Y no en pocas ocasiones el fiel o del arrendador actúan como persona propiciadora o ejecutora de actos fraudulentos.

Al municipio le compete también establecer el precio del vino: la llamada «postura» ${ }^{45}$. Los concejos bajomedievales tenían por costumbre establecer el precio del vino propio, del ajeno, del viejo y del nuevo. La postura del vino dependía de la producción (oferta), de la demanda, de la coyuntura económica, de la situación política (paz-guerra, alteración de la ruta marítima, estado de los caminos como consecuencia de tormentas o de la acechanza de los ladrones) y de las necesidades del consistorio. Existen dos maneras de establecer el precio del vino propio. En ocasiones se resolvía en las sesiones del concejo, escuchando las opiniones de los interesados. En otras, y es el caso del consistorio del Avia, se saca a remate la renta de la postura del vino. ¿Qué significa esto? Que la institución derivaba en un tercero, mediante subasta (postura) pública, el control de los precios de la venta del vino en los mesones y tabernas. Así las cosas coexistieron precios para el vino propio y para el foráneo, al por menor y al por mayor; todos regulados por el concejo. Pero es evidente que la existencia de este capítulo pretende frenar una de las modalidades del fraude más frecuentes: la manipulación que practicaban comerciantes o taberneros sobre el precio del vino, al alza o a la baja, desestabilizando el mercado ${ }^{46}$.

Siguiendo con la política de precios del vino propio ${ }^{47}$, las ordenanzas se expiden sobre el tipo de manipulación, especialmente la que mesoneros y taberneros ejercían sobre los envases. Solía suceder que una vez abierta la cuba, el propietario vendía su contenido a distintos precios obviando la postura establecida por el concejo. Una muestra más de que los controles impuestos no son suficientes porque la picardía formaba parte de las estrategias de la venta al consumidor. Era literalmente imposible controlar estas actuaciones, y aunque se realizaban visitas a bodegas, mesones, tabernas, etc., el concejo no puede frenar ni contener este tipo de prácticas, a pesar de las elevadas penas que se establecieron. En realidad es difícil fijar con cierto grado de realidad qué caldo se consume y cuál es su verdadera procedencia; si el precio que paga el consumidor es el oficial o el oficioso, etc. No huelga decir que la fama que persigue a bodegueros y taberneros en la literatura no es exagerada

45 «Que se remate la renta de la postura del vino», Copia de las ordenanzas de la villa de Ribadavia, AHRG, legajo 24330, f. 101r, 102r.

46 «Que ninguna persona venda el vino a más precio que el ordenado», Copia de las ordenanzas de la villa de Ribadavia, AHRG, legajo 24330, f. 104v-105r.

47 «Que una vez abierta una cuba, después de abierta, no puede subir el precio a que la abrió», Copia de las ordenanzas de la villa de Ribadavia, AHRG, legajo 24330, f. 104v. 
porque es, precisamente, en estos recintos donde el fraude campa a sus anchas. Establecer ordenanzas restrictivas y con elevadas penas es como «poner puertas al campo»: una pretensión casi imposible para una administración donde todo mecanismo de control «hace agua por doquier».

Dentro del universo de la venta al menudeo y, sobre todo, en relación a los espacios donde se expide alimento y bebida las autoridades establecen férreas normas de sanidad como medio de evitar la proliferación de enfermedades que pudieran afectar a la población ${ }^{48}$. La limpieza de estos sitios también es objeto de regulaciones. Esta normativa resulta de interés por dos cuestiones. Una, sitúa a la mujer como artífice y trabajadora de las tabernas; es decir, la mujer queda integrada en el mercado laboral urbano pero en actividades secundarias que se pueden considerar como una extensión de la función que la ley y la realidad le adjudican: el ámbito doméstico; observándose además cómo la situación legal de la mujer es utilizada para manejar un negocio de dudosa reputación económica y moral como es la taberna, tantas veces cantada por los goliardos y entendida como lugar de ocio, engaños, juegos, prostitución y delitos. Y la otra cuestión a destacar es cómo el concejo vela por la salud pública, tal y como ya se mencionó, en la medida que exige limpieza y el uso de enseres y complementos a fin de lograr un cierto estado de salubridad. Asimismo es especialmente curioso que la legislación se interese por los manteles, porque da idea de la existencia de ciertas normas sociales a la hora de servir una mesa en sitios que, en principio, no exigen ninguna etiqueta. Un lujo para estos recintos que la documentación, las fuentes literarias y la bibliografía describen como tugurio ${ }^{49}$.

Sin embargo, los mesones y las tabernas suscitan otro tipo de dilemas ${ }^{50}$. En aquellos lugares las mezclas entre vinos de diversas calidades y procedencias es una práctica cotidiana y creciente. Lógico, «el negocio es el negocio» y el tabernero o la tabernera, como buenos embaucadores, mezclan caldos malos con buenos o los nuevos con los viejos para poder vender un producto de baja calidad a un precio más elevado o para obtener una mayor rentabilidad del vino bueno. Es la «pescadilla que se muerde la cola»: unos regulan y otros defraudan; y ante la propagación de los fraudes, quienes regulan promulgan nuevas ordenanzas preventivas, con lo que se inicia nuevamente la cadena. Asimismo, se introduce en el texto de las ordenanzas una cuestión que no es menos importante: la manipulación del contenido de las cubas, que

48 «Que las bodegoneras (taberneras) y mujeres que vendieren vino y alimentos en las tabernas las tuvieren limpias, con sus platos, codillas y manteles», Copia de las ordenanzas de la villa de Ribadavia, AHRG, legajo 24330, f. 102r. Ver también RIVERA MEDINA, 174 (Bayona, 2009): 10-12. ROSO DÍAZ, 2001: 810-813.

49 RIVERA MEDINA, 6 (San Sebastián, 2010): 625-627.

50 «Que la persona que venda vino atabernado, no venda de dos cubas, excepto si fuera una de blanco y otra de tinto, ni haya mezcla del buen vino con el malo», Copia de las ordenanzas de la villa de Ribadavia, AHRG, legajo 24330, f. 103v. ROSO DÍAZ, 2001: 815. 
ya se ha explicado con anterioridad. Y es precisamente eso a lo que nuevamente se refiere el texto, porque estas trampas son aceptadas por todos, ya que con el engaño obtenían rentabilidad todas las partes involucradas. No obstante, el concejo, en una actitud que parece de cierta ingenuidad, pretende poner coto a estas prácticas, siendo que jamás dispuso ni del personal ni de los instrumentos suficientes para evitar que los vinos mezclados se vendiesen en el mercado local o se exportasen.

\section{Ordenamientos sueltos}

La recopilación de ordenamientos antiguos realizada en 1517 muy pronto superó lo legislado, porque pocos años más tarde aparecen lo que denominaremos ordenamientos sueltos: regulaciones que se promulgan en un determinado momento para solventar algún exceso o abuso pero que no están contenidas en un «corpus», y que al parecer tienen como finalidad reafirmar o reconfirmar lo dispuesto en años anteriores. Es de advertir que la actividad vitivinícola de la villa de Ribadavia se va desarrollando por cauces que muchas veces traspasan la frontera jurídica, por lo que su concejo no duda en establecer de forma continuada regulaciones para frenar o al menos paliar los perjuicios, en pos del buen gobierno de la villa.

Las regulaciones a las que se hace referencia tratan especialmente varios temas: la intromisión en los viñedos; el tiempo de la vendimia; el estado de las existencias de la oferta local del vino; la venta en los arrabales; la venta al menudeo o por menudo; los pesos, medidas y precios; la introducción de vinos de «fuera parte»; y los tipos de vinos susceptibles de ser importados. Estas regulaciones son de interés por el momento y la situación en que se producen, demostrando la necesidad patente, casi obsesión, del ayuntamiento por reglamentar a medida que la realidad de las actuaciones supera a la legalidad vigente. Al mismo tiempo se comprueba que al cambiar una situación, el concejo genera nuevas reglas de convivencia económica.

Siguiendo la dinámica del viñedo y en defensa de la propiedad privada, el consistorio no duda en confirmar una ordenanza antigua referida a las penas que padecerán aquellos que osaran introducirse en los viñedos en la época inmediatamente anterior a la vendimia. Al parecer, y como ya se ha señalado, era una práctica común invadir el viñedo ajeno de día o de noche. Aunque en esta ocasión la regulación detalla el perfil de los invasores: hombre, mujer, moza o mozo, es decir, personas mayores de doce o trece años con habilidad y sagacidad para cometer un delito, y con posibilidades de utilizar de manera rentable su botín ${ }^{51}$.

51 Libro de Foros Antiguos de Ribadavia (1524-1541), MER, f. 112v. Ribadavia, julio de 1529. Penado con diez días de cárcel y doscientos maravedíes de multa. 
Con la misma tónica la casuística refleja los desencuentros entre propietarios o arrendadores de viñedos y el concejo a la hora de acordar la fecha de comienzo de la vendimia. En 1529 los viticultores aducen que la vid estaba demasiado madura, y que de no comenzar la vendimia, el vino obtenido no sería tal, sino vinagre. A pesar de la opinión del sector, el consistorio no duda en determinar para diez días más tarde la fecha de comienzo de la vendimia, imponiendo penas muy duras a quien se aventure a cosechar antes de la fecha señalada52.

Otro punto que requirió de ordenamientos periódicos fueron los pesos y medidas, y los precios. Fue constante la necesidad de establecer la postura del caldo, y también se hizo imprescindible instaurar controles en los envases de los vinos. El consistorio recibe continuamente informaciones sobre la alteración de medidas y capacidades, siendo unas mayores que otras, ordenando que nadie pudiese tener en su poder medidas propias y que sólo se utilizarían las estipuladas por la autoridad, siendo el procurador el encargado de «marcar y sellar con la marca del concejo todas las medidas». La necesidad de controlar los pesos y medidas fue tal que se llega a ordenar visitas a los lugares donde se asisten estas cuestiones, para inquirir a gestores sobre la proporción de las mismas; visitas que llegaron a ser semanales ${ }^{53}$. Además, en la década de 1530 se reitera la orden de elaborar una tabla con las medidas que se han de utilizar para la venta al menudo o menudeo: azumbre, medio azumbre y cuarto azumbre o cuartillo ${ }^{54}$.

Asimismo, estos ordenamientos sueltos ponen de relieve la actitud del concejo ante los movimientos de la oferta local en torno a la comarca y, especialmente, en relación a los arrabales, como ya señalara la recopilación de 1517. Una cuestión difícil de solucionar porque las fronteras nunca fueron materiales sino jurídicas. Era inevitable que los vecinos y residentes de la villa o de los arrabales transitaran por uno u otro ámbito, deambulando con mercancías y, por supuesto, con productos básicos para la dieta alimenticia como el vino, el aceite o el pescado. Aunque las prescripciones municipales prohibiendo estos intercambios son antiguas, no por ello son menos reiteradas. El tráfico ilegal de mercancías entre ambos ámbitos desborda las regula-

52 Libro de Foros Antiguos de Ribadavia (1524-1541), MER, f. 113v. Ribadavia, 7 de setiembre de 1529. Libro de Ayuntamiento (1541-1559), MER, f. 3. Ribadavia, 10 de noviembre de 1541.

53 Libro de Cuentas de los Procuradores Generales de la Villa de Ribadavia, AHPO, Caja 325, f. 113r. Ribadavia, 23 de octubre de 1523. Libro de Foros Antiguos de Ribadavia (1524-1541), MER, f. 131. Ribadavia, 16 de setiembre de 1531. Libro de Ayuntamiento (1541-1559), MER, f.2 Ribadavia, 10 de noviembre de 1541.

54 Libro de Foros Antiguos de Ribadavia (1524-1541), MER, f. 160. Ribadavia 23 de marzo de 1532. 
ciones consistoriales. No obstante, el ayuntamiento regula una y otra vez sobre el mismo extremo ${ }^{55}$.

Así las cosas, las actuaciones sobre la existencia de excedentes locales cambian con cada vendimia y su correspondiente proceso de elaboración. De este modo, ante la excesiva oferta de vino propio el concejo prohíbe la introducción de vino de «fuera parte», porque al parecer el mercado se convulsionaba ante el bajo precio de la oferta foránea ${ }^{56}$. En otros momentos, cuando por diversos motivos la vendimia no es buena o abundante, se autoriza la entrada de vinos foráneos. Así sucede en 1524, cuando el concejo declara que «por el tiempo se perdio la bendimia» ${ }^{57}$. Si esto sucedía se autoriza el libre comercio de vinos foráneos, dejando claro que los caldos introducidos no debían proceder de la zona del río Miño ${ }^{58}$. Sin embargo, se permite la introducción de otras clases y procedencias de caldos, matizando que no se autorizaría su venta sin la previa petición de licencia, mientras existiera vino propio. Esta situación genera a lo largo del periodo una amplia regulación, sobre todo relativa al vino tinto «que no pueden meter ni metan vino tinto de fuera de la dha villa de ninguna parte e calidad». Al parecer, esta referencia explícita sobre el vino tinto responde a que en la villa, probablemente, por esas fechas produjo más vino de varietales tintos que de blancos ${ }^{59}$.

\section{CONCLUSIÓN}

El afianzamiento de los centros urbanos y del poder local durante la Baja Edad Media favorece la aparición y expansión de un sistema cerrado de mercado que comenzaba con una fuerte protección de la actividad primaria y de la de transformación, y concluye, aparentemente, con el blindaje de las actuaciones en el mercado mediante regulaciones que convierten a los concejos con sus prácticas monopolistas en los árbitros de la situación. Los concejos en interés del «buen gobierno» y en defensa de sus vecinos legislaron ordena-

55 Libro de Foros Antiguos de Ribadavia (1524-1541), MER, f. 116. Ribadavia, 7 de abril de 1530.

56 Libro de Foros Antiguos de Ribadavia (1524-1541), MER, f. 27. Ribadavia 10 de octubre de 1523; f. 29. Ribadavia, 23 de octubre de 1523.

57 Libro de Foros Antiguos de Ribadavia (1524-1541), MER, f. 61. Ribadavia, 11 de junio de 1525.

58 Libro de Foros Antiguos de Ribadavia (1524-1541), MER, f. 75. Ribadavia, 24 de septiembre de 1526.

59 Libro de Cuentas de los Procuradores Generales de la Villa de Ribadavia, AHPO, Caja 325, f. 112r. Ribadavia, 23 de octubre de 1523. Libro de Foros Antiguos de Ribadavia (15241541), MER, f. 11. Ribadavia, de noviembre de 1529; f. 16. Ribadavia, de octubre de 1531; f. 153. Ribadavia, 13 de enero de 1531. Libro de Ayuntamiento (1541-1559), Arquivo Municipal de Ribadavia. MER: Depósito Rubén García Álvarez, 54/02, f. 44. Ribadavia, 1 de febrero de 1543. 
mientos que atienden a este fin siempre privilegiando lo propio frente a lo foráneo o importado. En este sentido, es evidente que para controlar la política de mercado y, por ende, la política de abastecimiento local no dudaron en establecer regulaciones municipales en defensa del viñedo en una doble faz: protegiendo los intereses de las propiedades privadas conocedores de la vulnerabilidad de las plantas de cara a la vendimia, esto es, de puertas adentro sancionando con dureza las invasiones de los viñedos; pero también desde lo público , es decir, multando o penando el fraude en los trasiegos de uvas y, más tarde en los intercambios y en la calidad de los caldos. A partir de esta primera estrategia, se organiza un rígido sistema jurídico para las épocas de vendimia, de la elaboración y de la guarda —entendida esta última, como depósito de vinos propios o ajenos-. Pero el grueso de la legislación concejil se referirá al comercio al por mayor y al menudo como así también a las condiciones de abastecimiento, de distribución y de consumo del vino.

Desde la promulgación del Fuero, marco de referencia para el desarrollo de la vida municipal, queda patente que el vino de Ribeiro juega un papel que excede el propio ámbito local. Luego, la legislación no se limitaría a observar sólo las prácticas vitícolas sino y, especialmente, los mecanismos de abastecimiento local unidos a los correspondientes al comercio. El vino de Ribeiro inicia una escalada, desde el siglo XII, en el comercio internacional participando activamente de los circuitos comerciales, y correspondió a su concejo coordinar o articular los mecanismos que proporcionaran rendimientos o utilidades económicas a la villa. Dato nunca menor porque hablar de concejos es hacerlo de clases privilegiadas, sobre todo en una zona donde prima el sistema de foro o arrendamiento.

Con el paso de los siglos Bajomedievales, sus majestades los Reyes Católicos dan legitimidad al Fuero a través de una real orden que confirma, entre otras cuestiones, que el circuito del vino de Ribeiro satisface a las autoridades y convenía a los intereses de la propia villa. Así las cosas, queda en manos del concejo el preservar y proteger los diversos ámbitos de la actividad, en suma, arbitrar las medidas necesarias para preservar un dinamismo comercial que era vital para la economía de la villa. Entonces, partiendo del sector primario se regulan los controles al viñedo, promoviendo resoluciones que tienen que ver con la protección en época de vendimia y la incursión de desconocidos en las parcelas. Posteriormente, lo hacen en referencia a la elaboración, envasado y conservación hasta su salida a los mercados para finalmente, establecer provisiones, las más amplias, sobre su distribución, su comercio y su consumo. Ahora bien, cabe preguntarnos si estas medidas fueron efectivas.

En principio, no se debería dudar ni de la intención del concejo ni de la funcionalidad de las normativas. No obstante, esta política que se puede calificar de intervencionista, proteccionista y monopolista no parece haber surtido el efecto deseado dada la cantidad y tono de las regulaciones, y de sus respectivas penas. No es menos cierto que el fraude tuvo su parte del pastel 
como que tampoco fue posible «poner puertas al campo» por muchas y variadas medidas y por grandes penas que se aplicaran. El fraude fue parte activa en el sistema y frente a estas prácticas los concejos se encuentran impotentes. Cierto es que impulsaron guardas en las viñas y en las entradas de la ciudades pero, también es evidente que las regulaciones se saltan con gran facilidad porque no se pudieron instrumentar los mecanismos de control suficientes y efectivos para solventar el problema.

Por otra parte, los viticultores, los toneleros, los guardas, los taberneros, las bodegoneras, los arrieros y otros grupos asociados a la actividad se muestran participativos con las prácticas ilícitas. De todo lo cual resulta que aunque el concejo se mostrara estricto en relación a los trasiegos de caldos entre la villa y sus arrabales; restrictivo con las introducciones de caldos foráneos estableciendo época de libertad y veda; así como firme con la obligatoriedad de pedir licencia para las importaciones realizadas en tiempos de veda; todas estas prescripciones sólo fueron un parche en las fronteras jurídicas bajomedievales, y el concejo no tuvo éxito o al menos su éxito fue discreto. Sobre todo en una villa como Ribadavia a donde llegaban factores y comerciantes pontevedreses en busca del preciado caldo que, sin duda, fue junto al pescado mercancía de su comercio.

El vino de Ribadavia se convirtió en el Bajomedievo objeto de deseo de propios y extraños. De propios porque dio vitalidad y dinamismo a la villa y a los vecinos; de ajenos, por ser mercancía demandada en el circuito internacional. Dada la conjugación de estos factores, los autócratas locales impusieron sus reglas a fin de lograr una estabilidad en defensa de su fortuna. De ahí tanta intervención, tanto ordenamiento que son reflejo de una mentalidad, de una época y de unos intereses; los intereses de un grupo y de sus redes que aspiraron a obtener cuando no a revalidar el control de poder municipal.

\section{BiBLIOGRAFÍA}

Antonio Rubio, Gloria de, "El vino en el ámbito de la Galicia medieval”, en Actas de la Cultura del vino. Primer Congreso Peninsula, Santiago de Compostela, CSICInstituto de Estudios Gallegos “Padre Sarmiento”, 2005; 131-147.

Antonio Rubio, Gloria de, “Juderías gallegas del Miño y sus relaciones con las comunidades judías portuguesas al norte del Duero”, Porto, Aforamento, 2006.

Antonio Rubio, Gloria de, Los judíos de Ribadavia: la judería de Ribadavia y sus personajes en los siglos XIV-XV, Santiago de Compostela, Lostrego, 2004.

Arízaga Bolumburu, Beatriz, "La actividad comercial de los puertos vascos y cántabros medievales en el Atlántico”, Historia, Instituciones y Documentos, 35 (Sevilla, 2008): 25-43. 
Armas Castro, José, Pontevedra en los siglos XII a XV. Configuración y desarrollo de una villa marinera en la Galicia Medieval, Pontevedra, Fundación Pedro Barrié de la Maza, 1992.

Ayerbe Iríbar, María Rosa, “Las ordenanzas municipales de San Sebastián de 1489: Edición crítica”, Boletín de estudios históricos sobre San Sebastián, 40 (San Sebastián, 2006): 11-91.

Cantera Montenegro, Enrique, "El pan y el vino en el judaísmo antiguo y medieval”, Espacio, Tiempo y Forma. Serie III, Historia Medieval, 19 (Madrid, 2007): 13-48.

Cantera Montenegro, Enrique, “Los judíos riojanos y el cultivo de la vid”, Cuadernos de Historia de España, 84 (Buenos Aires, 2010): 39-59.

Castro Pérez, Xavier, A la sombra ejemplar de los parrales. Cultura del vino en Galicia y otros espacios peninsulares, Gijón, Trea, 2006.

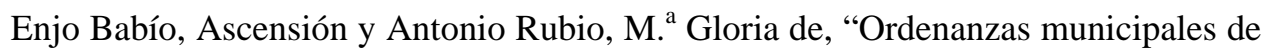
Ourense en el siglo XV”, Cuadernos de Estudios Gallegos, 119 (Santiago, 2006): 211-230.

Enríquez Fernández, Javier et al., "Colección Documental del Archivo Histórico de Bilbao (1300-1473)”, en Fuentes Medievales Documentales del País Vasco, San Sebastián, Eusko Ikaskuntza, 1999, n. ${ }^{\circ} 90$.

Estévez Pérez, José Ramón, “Crónica de Froissart. Defensa y toma de Ribadavia (1386)”, Cadernos de Ribadavia, 10 (Ourense, 2001): 11-91.

Ferreira Priegue, Elisa, "Galicia en la Marisma de Castilla: la dinámica de los intercambios mercantiles”, en Beatriz Arízaga Bolumburu y Jesús Ángel Solórzano Telechea, Ciudades y villas portuarias del Atlántico en la Edad Media, La Rioja, Instituto de Estudios Riojanos, 2005; 165-186.

Ferreira Priegue, Elisa, Galicia en el comercio marítimo medieval, Santiago de Compostela, Fundación Pedro Barrié de la Maza, 1988.

García Tato, Isidro y Suárez Piñeiro, Ana María, La cultura del vino. Primer Congreso Peninsular, Santiago de Compostela, CSIC-Instituto de Estudios Gallegos "Padre Sarmiento", 2005.

Gelabert González, Juan Eloy, "Problemas de comercialización de los vinos de Ribero de Avia en los siglos XVII y XVIII”, Liceo Franciscano, 85-86-87 (Santiago, 1976): 151-169.

Huetz de Lemps, Alain, “Apogeo y decadencia de un viñedo de calidad: el de Ribadavia”, Anuario de Historia Económica y Social,18 (Madrid, 1968): 207-225.

Huetz de Lemps, Alain, Vignobles et vins du Nor-Ouest de l'Espagne, Burdeos, Institut Geographie Faculté des Letres, 1967.

Jurado, Augusto, Las voces del vino y la vid, Madrid, C\&G, 2001.

Ladero Quesada, Miguel Ángel, Las Ferias de Castilla. Siglos XII a XV, Madrid, Comité Español de Ciencias Históricas, 1994. 
Lanza García, Ramón, “El viñedo en la España Cantábrica: una larga tradición ahora renovada”, en Congreso Internacional de AEHE, Sevilla, Universidad Pablo de Olavide, 2011; 1-25.

López Carreira, Anselmo, Acidade de Ourense no sécalo XV. Sociedade urbana na Galicia baixomedieval, Ourense, Diputación de Ourense, 1998.

López Martínez, Amalia, Losada Meléndez, María José y Enjo Nabío, María Asunción, “O Foro de Ribadavia”, Cadernos de Ribadavia, 20 (Ourense, 2009).

López Sabatel, José Antonio, “Cultivos agrícolas en la Ribeira Sacra durante los siglos XIV y XV”, Espacio, Tiempo y Forma. Serie III, Historia Medieval, 20 (Madrid, 2007): 183-198.

López Sabatel, José Antonio, “Paisaje agrario y prácticas agrícolas en la Ribeira Sacra (Galicia) durante los siglos XIV y XV”, Anuario de Estudios Medievales, 38 (Barcelona, 2008): 213-234.

López Villalba, José Miguel, “El abastecimiento del vino y su política proteccionista en el Alto Tajo (siglos XIV-XV)”, Espacio, tiempo y forma. Serie III, Historia Medieval, 24 (Madrid, 2011): 143-183.

Porras Arboledas, Pedro Andrés, "El derecho marítimo en el Cantábrico durante la Baja Edad Media: Partidas y Rôles D’ Oléron”, en Beatriz Arízaga Bolumburu y Jesús Ángel Solórzano Telechea, Ciudades y villas portuarias del Atlántico en la Edad Media, La Rioja, Instituto de Estudios Riojanos, 2005; 231-255.

Rivera Medina, Ana María, “Las Tabernas en Bilbao en la última Edad Media”, Bulletin du Musée Basque, 174 (Bayona, 2009): 5-22.

Rivera Medina, Ana María, "Del mar a la taberna: Los vinos en Bilbao (Ss. XVXVII). Tradición, modernidad y patrimonio”, Itsas Memoria. Revista de Historia Marítima del País Vasco, 6 (San Sebastián, 2010): 615-627.

Rivera Medina, Ana María, "El paisaje vitivinícola en las ordenanzas vizcaínas: Bilbao (Ss. XIV-XVI)”, Studivm, 14 (Zaragoza, 2008): 407-424.

Rivera Medina, Ana María, "La vitivinicultura española en los siglos XIV-XVII. Una mirada al caso de Bilbao”, Cuadernos de Historia de España, 83 (Buenos Aires, 2009): 187-223.

Rivera Medina, Ana María, "Producción local, abastecimiento urbano y regulación municipal: El marco legal del vino en Bilbao (S. XIV-XVI)”, Espacio, Tiempo y Forma. Historia Medieval. Serie III, 19 (Madrid, 2006): 233-264.

Rivera Medina, Ana María, “Trujeron ribadavias a la villa: El vino de Ribeiro en Bilbao (1399-1550)”, Cadernos de Ribadavia, (2011).

Rivera Medina, Ana María, “Vid, viñedos y vino en Sefarad: Cultivo, elaboración y comercio de un vino diferenciador”, Espacio, tiempo y forma. Serie III, Historia Medieval, 20 (Madrid, 2007): 199-233.

Rivera Medina, Ana María, La civilización del viñedo en Bilbao (1300-1650), La Coruña, Netbiblo-UNED, 2011. 
Rodrigo Estevan, María Luz, "Por guardar la provisio necesaria a la dita ciudad e el provecho comun de la gente popular: la preocupación por el abastecimiento y la calidad del vino en el siglo XV", en XIX Jornadas de Viticultura y Enología Tierra de Barros, Badajoz, Centro Cultural Santa Ana, 1997; 571-582.

Roso Díaz, José, "Sobre vinos aguados, malos venteros y otras estafas tabernarias. Un motivo folklórico en la literatura del Siglo de Oro”, en XXII Jornadas de Viticultura y Enología. Tierra de Barros, Badajoz, Centro Cultural Santa Ana, 2001; 809-822.

Rössler, Mechtild, "Los paisajes culturales y la Convención del Patrimonio mundial cultural y natural: resultados de reuniones temáticas previas”, Lima, UNESCO, 2009; 47-55.

Santos, Xosé María: "Os territorios do vinho na Galiza. Contribuiçao á Geografía cultural do vinhedo e do vinho”, Douro. Estudos \& Documentos, 13, (Porto, 2011): 113-122.

Serna Vallejo, Margarita, "El derecho marítimo en el Cantábrico durante la Baja Edad Media: Partidas y Rôles d'Oléron”, en Beatriz Arízaga Bolumburu y Jesús Ángel Solórzano Telechea, Ciudades y villas portuarias del Atlántico en la Edad Media, La Rioja, Instituto de Estudios Riojanos, 2005; 231-255.

Serna Vallejo, Margarita, "Los estímulos jurídicos a la relación comercial en los siglos medievales: privilegios y ordenamientos”, en José Ignacio Iglesia Duarte (coord.), El comercio en la Edad Media, Logroño, Institutos de Estudios Riojanos, 2006; 289-317.

Serna Vallejo, Margarita, Los rôles d'Oléron. El coutumer marítimo del Atlántico y del Báltico de la época medieval y moderna, Santander, Centro de Estudios Montañeses, 2004.

Solórzano Telechea, Jesús Ángel, "Documentación Medieval de la Biblioteca Municipal de Santander. Manuscritos originales (945-1519)", Anejos de AMEA. Anales de Historia Medieval de la Europa Atlántica, n. ํ 1, Santander, Diputación, 2007.

Solórzano Telechea, Jesús Ángel, Patrimonio documental de Santander en los archivos de Cantabria (1253-1515), n. ${ }^{\circ}$ 43, Santander, Diputación de Cantabria, 1998.

Viúla de Faria, Tiago y Miranda, Flavio, "Pur bonne alliance et amiste faire: Diplomacia e comércio entre Portugal e Inglaterra no final da Idade Média”, CEM. Cultura, Espaço \& Memoria. Revista do CITCEM, 11 (Porto, 2010): 109-127.

Recibido: 25-12-2011

Aceptado: 31-07-2012 